\title{
Gestão de Resíduos de Madeira: estudo em empresa de estofados na Zona da Mata, Minas Gerais.
}

\author{
Management of Wood Residues: study in a upholstery company in Zona da Mata, \\ Minas Gerais.
}

COUTO, Marcela Moreira; Mestre; Universidade Federal de Minas Gerais.

marcelamcouto20@gmail.com

PEREIRA, Andréa Franco; Doutor; Universidade Federal de Minas Gerais.

andreafranco@ufmg.br

\section{Resumo}

Esse artigo apresenta os resultados de um estudo de caso de pesquisa que investiga a gestão dos resíduos de madeira provenientes das indústrias moveleiras, mais especificadamente do segmento de estofados, com intuito de propor soluções que visem à minimização desses resíduos. A interdisciplinaridade é indispensável, pois, a interação entre a engenharia, gestão e design são essenciais para estudar as formas de se reduzir os resíduos de madeira na indústria de estofados. A empresa, objeto de estudo, está localizada na região da Zona da Mata, Minas Gerais. A metodologia empregada é qualitativa, de natureza aplicada e descritiva, em que se optou, como objeto, pelo estudo de caso. A partir dos resultados, pôde-se concluir sobre a necessidade de implantação mais robusta de ferramentas de gestão ambiental, bem como do design ou redesign dos produtos, visando à redução do resíduo na fonte e facilitando o gerenciamento do resíduo na produção.

Palavras Chave: Resíduos de madeira; gestão ambiental; segmento de estofados.

\begin{abstract}
This article presents the results of a research case study that investigates the management of wood residues from the furniture industries, more specifically the upholstery segment, in order to propose solutions aimed at the minimization of these residues. Interdisciplinarity is indispensable because the interaction between engineering, management and design are essential to study ways of reducing wood waste in the upholstery industry. The company, object of study, is located in the region of Zona da Mata, Minas Gerais. The methodology used is qualitative, of an applied and descriptive nature, in which the case study was chosen as the object. From the results, one can conclude on the need for a more robust implementation of environmental management tools, as well as the design or redesign of the products, aiming at the reduction of waste at source and facilitating the management of waste in production.
\end{abstract}

Keywords: Waste wood; environmental management; segment of upholstery. 


\section{Introdução}

A gestão de resíduos sólidos é um dos problemas ambientais mais graves da sociedade. $\mathrm{O}$ encurtamento do ciclo de vida dos produtos, reflexo da obsolescência programada, do consumismo desenfreado, são fatores que se relacionam com aumento da quantidade de resíduos produzida. Além disso, muitos desses resíduos têm uma destinação inadequada causando prejuízos para o meio ambiente. Preocupado com essa questão, o Brasil criou em 2 de agosto de 2010 a Lei no 12.305/10 que instituiu a Política Nacional de Resíduos Sólidos (PNRS), definindo-se, assim, uma base para o país na implantação de uma gestão correta dos resíduos sólidos (ABRELPE, 2013).

Com a obrigatoriedade da lei, as indústrias necessitam se adequar ambientalmente, deste modo, muitas empresas estão revendo seus processos. Nesse contexto, Pereira, Carvalho e Pinto (2010) acrescentam que qualquer atividade industrial gera resíduos, tal fato não é diferente para a indústria moveleira. Essas autoras complementam ainda que, o resíduo de madeira apesar de possuir baixo nível poluidor, há outros fatores relacionados, como a ocupação de espaço pelos mesmos que também são causadores de problemas, podendo interferir no processo de produção como um todo.

A sustentabilidade do sistema de produção é um problema global que o governo, as indústrias e a sociedade enfrentam (DAIAN; OZARSKA, 2009). Sendo a indústria moveleira geradora de resíduos ela se insere nesse contexto. Ademais, há uma grande dificuldade por parte das pequenas e médias empresas (PMEs) desse setor no que se refere ao reaproveitamento da madeira, na minimização da geração e na destinação correta dos resíduos. As consequências causadas por essas dificuldades das PMEs são os impactos que a destinação inadequada dos resíduos de madeira traz para a saúde humana e o meio ambiente (LOPES, 2016).

Diante dessa perspectiva, o presente estudo investigará os resíduos de madeira provenientes das indústrias moveleiras, mais especificadamente do segmento de estofados, para posteriormente estudar soluções que visem minimizá-los. A empresa, objeto de estudo, é uma empresa de estofados localizada no interior de Minas Gerias, na região da Zona da Mata, cidade de Abre Campo.

A pesquisa foi delineada a partir da seguinte pergunta de partida: Quais são as possíveis ações para a diminuição do resíduo de madeira na indústria de estofados? A metodologia empregada tem abordagem qualitativa, de natureza aplicada e descritiva, em que se optou, como objeto, pelo estudo de caso, permitindo um amplo e profundo conhecimento da realidade e dos fatos pesquisados.

\section{Desenvolvimento}

\subsection{O setor moveleiro nacional e regional}

O Departamento de Pesquisas e Estudos Econômicos - DEPEC (2015) destaca que a maioria das empresas que atuam no setor de móveis no Brasil é de gerenciamento familiar e de pequeno porte, fato esse, que dificulta por vezes à prática de técnicas modernas de administração e controle. Existem também nesse setor, diversas empresas informais, como o caso das marcenarias.

Em relação ao desempenho do setor moveleiro, o mesmo é de grande relevância para a economia do Brasil, representam 5,6\% de participação na indústria e empregam 256 mil 
empregados. No país há 22,5 mil empresas de móveis, estando à maioria concentradas nas regiões sul e sudeste (DEPEC, 2015). Sobre o panorama nacional de móveis, Rosa et. al (2007) complementam que no Sul e Sudeste concentram-se o maior número de estabelecimentos, sendo que Minas Gerais representa $13 \%$, assim, esse estado esta na quinta posição no que se refere à quantidade de indústrias de móveis no Brasil.

Dentre as regiões de Minas Gerais, Ubá se destaca como o principal polo moveleiro do Estado e está situado na Zona da Mata mineira, distante $280 \mathrm{~km}$ de Belo Horizonte. A indústria moveleira é fundamental para a economia dessa região (Rosa et al., 2007). A Federação das Indústrias do Estado de Minas Gerais - FIEMG (2014) acrescenta que a indústria de móveis na Zona da Mata, tem grande valor no que tange à empregabilidade, representaram no ano de 2011, 17,2\% dos empregos industriais, tendo crescido de maneira incessante desde 2007.

\subsubsection{Segmento de estofados}

Dentre os diversos segmentos da indústria moveleira, encontram-se os móveis "estofados" (ABDI, 2008), foco do presente estudo. Para a ABNT (2004) a definição de sofá estofado é: "móvel estofado de um ou dois lugares, composto de assento e encosto, com ou sem braço". No ano de 2013, os estofados representaram 10,7\% do total da produção moveleira do Brasil (IEMI, 2016).

Alguns dos principais requisitos dos quais os clientes levam em consideração ao escolher o estofado são: design (funções de uso e estima e conforto), tecnologia, inovação, preço e durabilidade. Dessa maneira, os materiais empregados na estrutura, o tecido, a garantia e a manutenção do estofado, são fatores que devem ser levados em consideração para satisfazer os clientes e resguardá-los (FIALHO, 2011).

Com relação às características desse segmento em termos de inovações e tecnologias, afirma Fialho (2011, p.30): “[...] a tecnologia envolvida na produção de estofados é bastante rudimentar frente às tecnologias mais sofisticadas, utilizadas na produção de móveis planos". Para o mesmo autor, o processo de produção dos estofados é artesanal, com intensiva mão-de-obra e de máquinas tradicionais.

\subsection{Gestão de resíduos de madeira na indústria moveleira}

Para Koch et. al. (2014, p. 56), "as empresas, na busca da competitividade nacional e internacional necessitam de um processo de gestão de seus resíduos, no qual se preocupem com o meio ambiente". Em estudos realizados por Caetano, Depizzol e Reis (2017, p. 392) "[...] o setor moveleiro é um grande gerador de resíduos e os impactos ambientais ocasionados pela gestão inadequada deles (ou falta de gestão) são graves e merecem atenção".

O resíduo de madeira faz parte da classe II de resíduo e é classificado como sólido, seco, de decomposição orgânica e de origem industrial e apesar de não apresentarem periculosidade, não são inertes (AMBIENTE BRASIL (2007, citado por PEREIRA, CARVALHO e PINTO, 2009)). A estimativa anual a respeito da geração de resíduo de madeira no Brasil é de aproximadamente 30 milhões de toneladas. Cerca de $91 \%$ dos resíduos de madeira são provenientes da indústria madeireira enquanto a construção civil é responsável por 3\% e o meio urbano 8\% (TUOTO, 2009).

Além de tal classificação quanto à fonte de geração, Casagrande Jr. et al. (2004) rotulam os resíduos madeireiros quanto as suas características morfológicas, isto é, de acordo com as dimensões de suas partículas, em: pó, serragem, cepilho ou maravalha e lenha, conforme a tabela1: 
Tabela 1- Dimensões dos tipos de resíduos de madeira

\section{RESÍDUOS DE MADEIRA}

Pó

Serragem

Cepilho ou Maravalha

Lenha

\section{DIMENSÕES}

$<0,5$ milímetros

0,5-2,5 milímetros

$>2,5$ milímetros

Pedaços de madeira maciça ou chapas de tamanho variável

Fonte: Adaptado pela autora com base em Casagrande Jr. et al.(2004).

Em estudos realizados por Pereira, Carvalho e Pinto (2010), a classificação quanto à granulometria dos resíduos se deu de forma mais simples visando melhor compreensão pelos proprietários e funcionários de uma empresa. Essas autoras dividiram os resíduos madeireiros da seguinte forma:

Classificamos os resíduos dentro dos dois grupos: serragem e retalho. Para a serragem foram identificados tipos diferentes a partir da granulometria do material. [...] No caso dos retalhos foram criados dois grandes grupos: denominado pela equipe "ripas" e "aparas". Os mesmo foram subdivididos em ripas finas e grossa e aparas pequenas e graúdas. (PEREIRA; CARVALHO; PINTO, 2010, p. 5).

A tabela 2 apresenta três tipos mais comuns de destinação que é dada aos resíduos de madeira: deposição em aterros, incineração e reciclagem; e, além disso, apresenta também os impactos ambientais que cada uma dessas técnicas causam no ar (emissão de gases), na água (compostos tóxicos) e no solo (acúmulo de substâncias perigosas) (KOCH, 2012).

Tabela 2- Técnicas de gestão de resíduos de madeira e seus resultados para o meio ambiente

\begin{tabular}{|c|c|c|c|}
\hline \multirow{2}{*}{$\begin{array}{l}\text { Destinação dos } \\
\text { resíduos de madeira }\end{array}$} & \multicolumn{3}{|c|}{ Impactos Ambientais } \\
\hline & $\mathrm{Ar}$ & Água & Solo \\
\hline Deposição em aterros & $\begin{array}{l}\text { Emissões de gases com } \\
\text { efeito estufa, odores } \\
\text { desagradáveis. }\end{array}$ & $\begin{array}{l}\text { Contaminação do lençol } \\
\text { freático. }\end{array}$ & $\begin{array}{l}\text { Acúmulo de substâncias } \\
\text { perigosas no solo. }\end{array}$ \\
\hline Incineração & $\begin{array}{l}\text { Emissão de } \mathrm{CH}_{4}, \mathrm{CO}_{2}, \mathrm{SO}_{2} \text {, } \\
\text { dioxinas. }\end{array}$ & $\begin{array}{l}\text { Precipitação de } \\
\text { substâncias perigosas em } \\
\text { águas superficiais }\end{array}$ & $\begin{array}{l}\text { Escórias e cinzas provenientes } \\
\text { da incineração dispostas no } \\
\text { solo. }\end{array}$ \\
\hline Reciclagem & & Nenhum impacto ambi & \\
\hline
\end{tabular}

Fonte: Adaptado pelas autoras com base em Koch (2012); SEBRAE (2015b).

O SEBRAE (2015b) relata que dentre essas destinações dada aos resíduos, a mais correta é a reciclagem e deve ser praticada pelas empresas moveleiras devido ao seu impacto nulo ao meio ambiente. Entretanto, ressalta que o descarte faz parte da última etapa do ciclo de vida do produto, assim, outras estratégias podem e devem serem aplicadas na busca pela produção sustentável.

Boyle \& Baetz (1998) alegam que é indispensável que os gestores utilizem de algum sistema de suporte à tomada de decisão com foco na minimização de resíduos, reutilização e reciclagem para se chegar de fato em um sistema de gestão de resíduos eficiente, reduzindo custos e os impactos ambientais. 


\subsection{Ferramentas da Gestão Ambiental}

"O conhecimento dos resíduos gerados por uma empresa é de grande importância, tanto econômica quanto ambientalmente, uma vez que a organização sempre almeja reduzir desperdícios ao longo de todo o seu processo produtivo e minimizar os danos ambientais causados" (CAETANO; DEPIZZOL; REIS, 2017, p. 388).

Diante disso, as ferramentas de gestão ambiental têm papel fundamental na gestão de resíduos. Um novo paradigma foi se criando ao longo do tempo rumo ao desenvolvimento sustentável, isto é, legislações ambientais e consumidores mais exigentes demandam por uma mudança de comportamento das organizações frente ao meio ambiente.

\subsubsection{ISO 14000: Sistema de Gestão Ambiental}

A International Organization for Stardardization (ISO) criou à série ISO 14000 que trata exclusivamente de assuntos ambientais, estabelecendo diretrizes para à gestão ambiental nas organizações. A criação dessa série foi resultado da necessidade de se padronizar os processos que utilizam de recursos naturais e causam impactos ao meio ambiente, em 1993, a ISO cria então, o Comitê Técnico TC 207 com o objetivo de desenvolver normas da série 14000 (OLIVEIRA, 2009).

A ISO 14001 é a única certificável da série e de acordo com Oliveira (2009, p. 2), “[...] é a mais conhecida das normas da série 14000, que estabelece as diretrizes básicas para o desenvolvimento de um sistema que gerencie a questão ambiental dentro da empresa [...]".

Oliveira (2009) acrescenta que o cerne da ISO 14001 é identificar todos os impactos ambientais e por meio de metas e monitoramentos, elaborar um programa com intuito de reduzir esses impactos. Essa identificação, o gerenciamento e o controle das questões ambientais devem ser realizados de forma holística e buscando sempre à melhoria contínua (ABNT, 2015).

Visando à melhoria contínua, Barbiero (2014) diz que o ciclo PDCA do inglês (plan, do, check e act ) é uma ferramenta que serve como base metodológica para o SGA. A figura 1 mostra como o SGA se utiliza dos princípios do PDCA:

Figura 1- Sistema de Gestão Ambiental - Ciclo PDCA

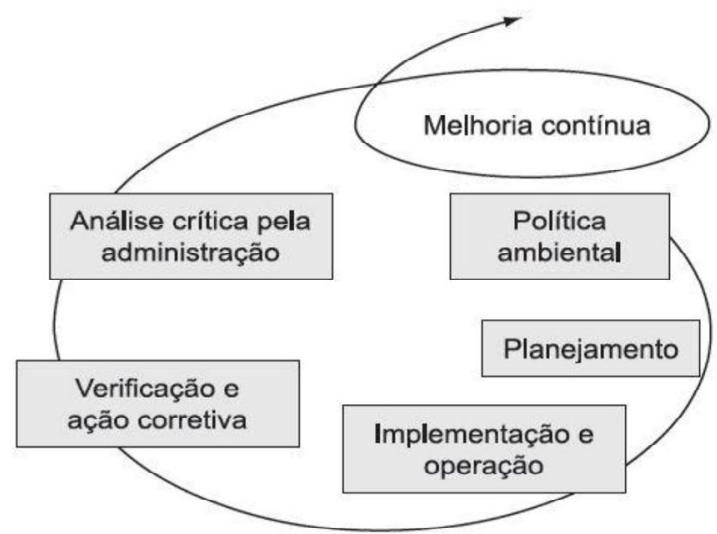

Fonte: Barbiero (2014). 
A Política Ambiental é definida em uma fase anterior à fase de Planejamento, isto é antes de se iniciar o ciclo PDCA, sendo indispensável à definição dessa política e de alguns requisitos gerais, pois, os mesmos servirão de base para as fases subsequentes (BARBIERO, 2014).

As fases do ciclo PDCA podem ser descritas, conforme Souza (2015), da seguinte maneira:

- Planejar (Plan): estabelecer os objetivos e processos necessários para atingir as metas, em concordância com a política ambiental da organização;

- Executar (Do): realizar de fato aquilo que foi planejado;

- Verificar (Check): controlar e monitorar processos em conformidade com a política ambiental, objetivos, metas, requisitos legais e relatar resultados;

- Agir (Act): programar ações necessárias para melhoria contínua do SGA.

O PDCA não tem fim, ele é cíclico e por isso, após as conformidades em cada ciclo, o mesmo pode-se repetir infinitas vezes dando enfoque em outros setores da empresa. Alguns benefícios são destacados por Oliveira (2009) com a implantação do SGA como o fortalecimento da imagem e a participação no mercado; a minimização de acidentes e sanções legais; redução no consumo de matérias-primas, água e energia; a facilidade na obtenção de licenças e autorizações; boas relações com a comunidade, e a certificação.

\subsubsection{Produção mais limpa $(P+L)$}

A Produção mais Limpa $(\mathrm{P}+\mathrm{L})$ é uma ferramenta da gestão ambiental que foi desenvolvida no final da década de 1980 pela United Nations for Industrial Development (UNIDO) e United Nations Environmental Program (UNEP). Desde então, centro nacionais vem sendo criados com intuito de estimular a $\mathrm{P}+\mathrm{L}$ nas organizações, no Brasil, apoiado pelo UNIDO e UNEP, o SENAI-RS hospeda o Centro Nacional de Tecnologias Limpas (CNTL), se tornando o grande responsável pela disseminação do conceito e aplicação da metodologia de $P+L$, através de capacitações, informação tecnológica, consultorias e eventos em diversos estados brasileiros (CEBDS, 2010; PEREIRA e SANT'ANNA, 2012).

A definição de $P+L$ é definida como a aplicação ininterrupta de uma estratégia ambiental de cunho preventiva e integrada aos processos, produtos e serviços a fim de melhorar a eficiência e minimizar riscos ambientais e aos seres humanos (UNEP, 2010). Pereira e Sant'Anna (2012) acrescentam que a $\mathrm{P}+\mathrm{L}$ visa eliminar a poluição ainda no processo produtivo, e não após o mesmo como é feito em abordagens do tipo fim de tubo que tem foco na ação corretiva.

Deste modo, é indispensável na $\mathrm{P}+\mathrm{L}$, a análise de cada etapa do processo produtivo para verificação de como esta sendo utilizadas às matérias-primas, a energia e a água, assim como a geração de resíduos, emissões e efluentes. Complementa Caetano, Depizzol e Reis (2017, p.386): "identificar os resíduos gerados na planta produtiva de um empreendimento, assim como quantificá-los, permite a análise mais eficiente quanto à escolha de alternativas e a proposição de estratégias para minimização ou não geração de resíduos na fonte".

A aplicação da $\mathrm{P}+\mathrm{L}$ se divide em três níveis, a Figura 2 apresenta o fluxograma de atuação da P+L. O primeiro nível é tido como prioritário e busca a Redução na Fonte, o nível 2, se refere à Reciclagem Interna e é feita quando os resíduos podem ser reutilizados dentro do próprio processo da organização e o nível 3 é a Reciclagem Externa (CNTL, 2003). 
Figura 2- Fluxo de atuação da metodologia da Produção Mais Limpa

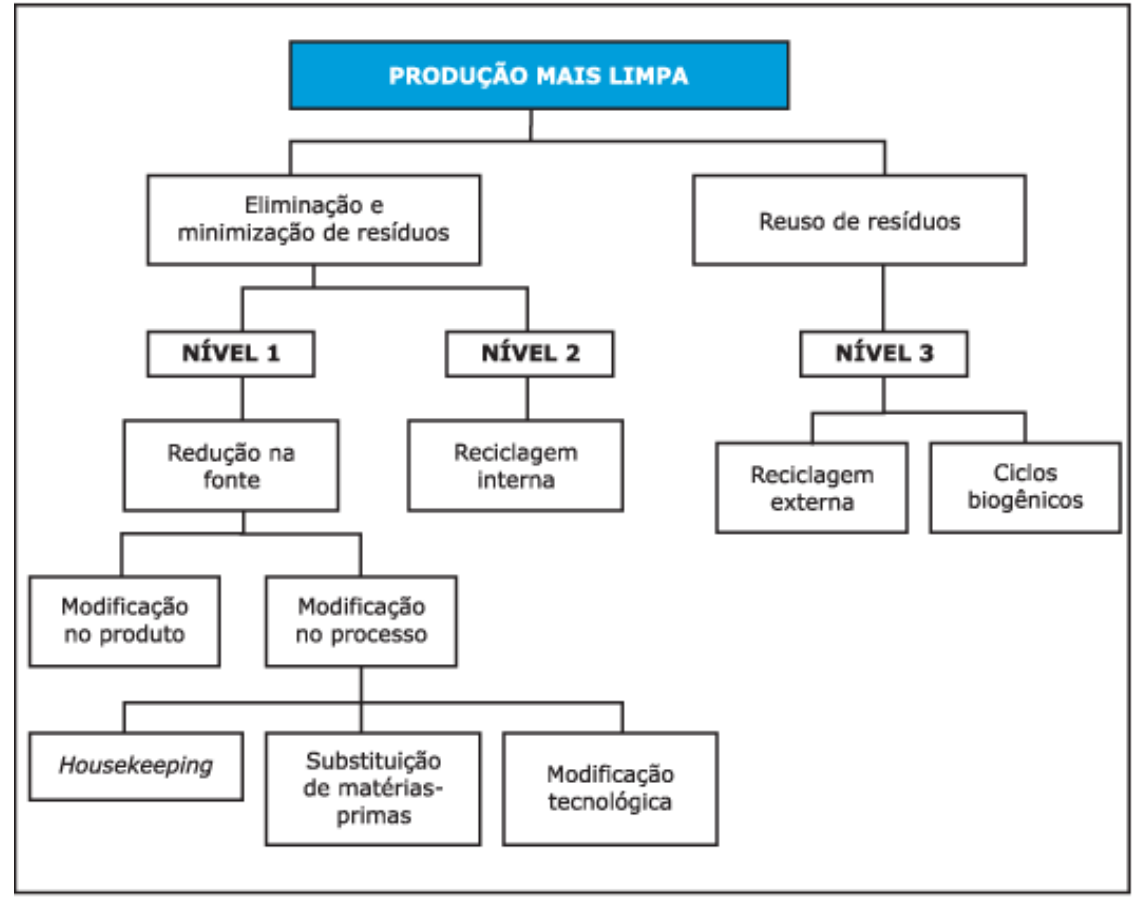

Fonte: CNTL (2003); SEBRAE (2015).

\section{Metodologia}

A pesquisa é de natureza aplicada, pois, para Silva e Menezes (2001, p.20) uma pesquisa dessa natureza tem por finalidade "gerar conhecimentos para aplicação prática dirigida à solução de problemas específicos".

Quanto à abordagem a pesquisa é qualitativa, pois, para Gil (1999), o uso dessa abordagem possibilita o aprofundamento da investigação dos fenômenos e das suas relações, por meio do contato direto com o caso estudado, de forma a perceber a individualidade e os significados múltiplos das questões.

A pesquisa é classificada como descritiva. Segundo Sampieri et al. (2006) estudos considerados descritivos, permitem descrever com precisão os fatos e fenômenos da realidade, bem como aprofundar sobre o tema em questão.

Por fim, quanto ao objeto de estudo, a escolha foi o estudo de caso. Conforme Yin (2001), o estudo de caso é marcado pelo estudo exaustivo dos objetos de investigação, permitindo um amplo e profundo conhecimento da realidade e dos fatos pesquisados, justamente o que se deseja neste trabalho.

Em relação às etapas da pesquisa, pode-se dividi-las em duas grandes etapas: etapa 1 (Revisão bibliográfica); etapa 2 (pesquisa de campo). A Figura 3 apresenta essas duas etapas: 
Figura 3- Macro etapas da pesquisa

Etapa 1: Revisão Teórica

\begin{tabular}{|c|c|}
\hline Pesquisa biliográfica; & $\begin{array}{c}\text { Suporte teórico para o trabalho } \\
\text { científico. }\end{array}$ \\
\hline \multicolumn{2}{|c|}{ Etapa 2: Pesquisa de Campo } \\
\hline $\begin{array}{c}\text { Diagnóstico da empresa objeto de } \\
\text { estudo por meio das técnicas de } \\
\text { coleta de dados; }\end{array}$ & $\begin{array}{c}\text { Identificação dos resíduos de madeira } \\
\text { e impacos ambientais. } \\
\text { Proposição de melhorias. }\end{array}$ \\
\hline
\end{tabular}

Fonte: Elaborado pelas autoras.

A primeira etapa, pesquisa bibliográfica, ofereceu suporte ao trabalho, utilizou-se principalmente do (Portal Brasileiro de Informação Científica - Portal CAPES; pesquisa na internet de acesso público (https://www.google.com.br/) e (https://scholar.google.com.br/), além de livros, sites de revista e governamentais.

A segunda etapa, que se trata da pesquisa de campo, realizou-se visitas in loco na empresa de estofados e por meio da observação direta, entrevista semiestruturada e aplicação de questionário tornou-se possível investigar a realidade dos fenômenos estudados, fazer um diagnóstico da empresa no que se refere ao gerenciamento dos resíduos de madeira.

\section{Estudo de caso}

Os resultados apresentados a seguir dizem respeito ao estudo de caso realizado em uma empresa de estofados localizada na região da Zona da Mata, Estado de Minas Gerais. A empresa possui 31 funcionários, e de acordo com a classificação do SEBRAE (2013) quanto ao número de funcionários, é considerada de pequeno porte. Atua há mais de dez anos no setor e atende os estados de Minas Gerais, Espírito Santo e Rio de Janeiro.

Vale ressaltar que a empresa não tinha dados históricos a respeito das quantidades de seus resíduos de madeira gerados, assim, os elementos fornecidos nessa seção são estimativas feitas a partir de informações do proprietário da empresa e do coordenador de produção.

\subsection{Produtos e resíduos de madeira: dados coletados}

A matéria-prima utilizada para a fabricação dos estofados é a madeira maciça de floresta plantada, o eucalipto e a madeira reconstituída, o Medium Density Fiberboard MDF, o último em pequenas quantidades quando comparado ao eucalipto. Além disso, a empresa fabrica cerca de 9 tipos de estofados, sendo os principais: "Ágata", "Rubi" e "Bahamas" (Figura 4) que juntos representam $70 \%$ da produção total. 
Figura 4- Principais estofados produzidos pela Empresa de estofados estudada

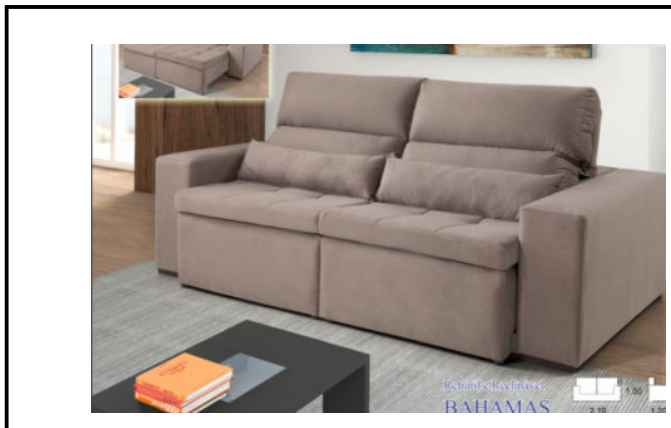

a. Estofado Bahamas

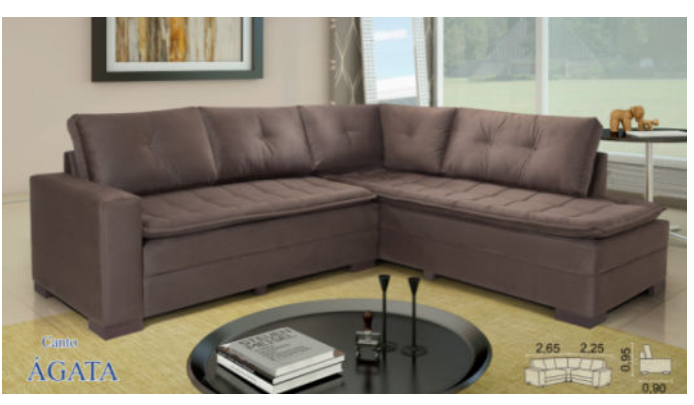

b. Estofado Ágata

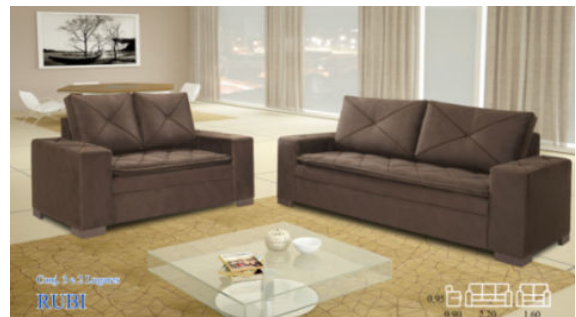

C. Estofado Rubi

Fonte: Empresa de estofados (2017).

Como o estudo aborda os resíduos de madeira, o enfoque no processo produtivo se deu na serraria. A Figura 5 mostra alguns tipos de resíduos de madeira da empresa. Para classificação desses resíduos usou-se como base estudos realizados por Pereira, Carvalho e Pinto (2010), uma classificação dos resíduos mais simples, dividindo-os em dois grandes grupos: serragem e retalhos. A (Figura 5.a), mostra os resíduos do tipo serragem com granulometrias diferentes e na (Figura 5.b) são os retalhos, que podem ser encontrados em vários tamanhos na empresa. Os resíduos de madeira se diferenciam dependendo do maquinário utilizado em cada etapa do processo na serraria.

Figura 5- Resíduos madeireiros da empresa

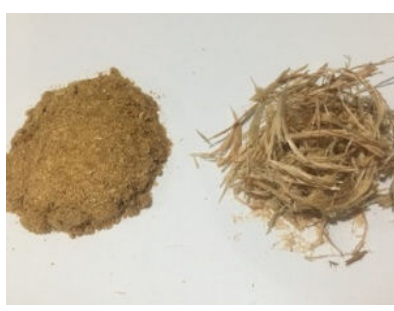

a. Serragens

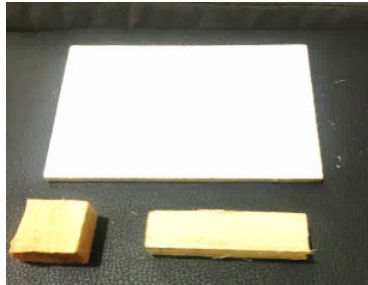

b. Retalhos

Fonte: Arquivo das autoras.

As estimativas das quantidades de resíduos de madeira na empresa estudada, no ano de 2016, estão apresentadas na Tabela 3. Em relação à destinação dada a esses resíduos, o 
proprietário informou que as sobras de madeira (retalhos com tamanhos diferentes) são recolhidas pela prefeitura a cada 10 dias aproximadamente, a caçamba com esses retalhos contém outros tipos de resíduos sólidos misturados aos de madeira. Quando questionado sobre o destino destes resíduos após a coleta da prefeitura, o proprietário disse que desconhecia. Ademais, explicou que a serragem é recolhida pelos silos até que os mesmos atinjam seu limite, a partir daí, são ensacados e vendidos para as granjas da região.

Tabela 3- Quantidade estimada dops resíduos madeireiros gerados no ano de 2016 na empresa

\begin{tabular}{cc}
\hline Principais resíduos de madeira & $\begin{array}{c}\text { Quantidade/ano } \\
\text { (volume) }\end{array}$ \\
\hline Retalhos & $77 \mathrm{~m}^{3}$ \\
Serragens & $180 \mathrm{~m}^{3}$ \\
\hline
\end{tabular}

Fonte: Elaborada pelas autoras.

\subsection{Ferramentas de Gestão Ambiental na empresa: SGA e P+L}

Apesar da empresa não conhecer sobre as ferramentas de gestão ambiental, isto é, não traçar estratégias sustentáveis, na prática utiliza-se de algumas técnicas da $\mathrm{P}+\mathrm{L}$, como por exemplo, a reciclagem interna e a reciclagem externa.

Para minimizar a geração na fonte, a empresa de estofados não utiliza nenhuma ação bem definida. Pôde-se observar que uma nova máquina de corte, com maior tecnologia agregada quando comparada as demais foi inserida ao processo na serraria, a mesma, faz cortes de forma menos manual que as outras, o operador insere a medida e a máquina realiza o corte automaticamente, evitando perdas tão grandes. Contudo, as máquinas manuais ainda são bastante usadas, pois, as automáticas não são capazes de atender a demanda e também não fazem alguns tipos de cortes.

Quanto à reciclagem interna, há um direcionamento para que os funcionários reutilizem sobras de madeira para produção de outro estofado. No entanto, pouco se tem feito nesse sentido, no que tange a treinamentos e conscientização destacando a importância dessa reutilização dos insumos, assim, muitas peças acabam ficando perdidas e não são aproveitadas devidamente.

Em relação à reciclagem externa, a empresa vende sua serragem para as granjas da região conforme mencionado anteriormente. A serragem é aspirada por meio de tubos ligados diretamente a um "silo vertical", após atingir sua capacidade limite o mesmo é aberto para ensacamento e posterior venda. Esse silo foi instalado recentemente na empresa, isso se deu porque o acúmulo de serragem no chão da serraria estava prejudicando o ambiente de trabalho, exigindo dos funcionários mais movimentações e esforços além, dos riscos a que os mesmos estavam submetidos. Nesse sentido, o primeiro passo foi dado em relação ao melhor gerenciamento de resíduos de madeira. É evidente, que apesar dessas práticas serem aplicadas na empresa, muito ainda dever ser feito para que de fato tenha processos voltados para desenvolvimento sustentável. 


\section{Conclusões}

A indústria moveleira tem papel fundamental na economia brasileira, todavia, a adequação das mesmas em relação às questões ambientais, frente a maior demanda tanto pelas legislações e exigências da população, se faz necessária. Logo, é preciso revisar o processo produtivo com as estratégias voltas à gestão ambiental, pois, tais estratégias não só proporcionam vantagens ambientais, como também financeiras e relacionadas à imagem da empresa.

A empresa de estofados analisada é de pequeno porte e assim como na grande maioria das PME's muitas são as dificuldades encontradas na própria gestão do negócio, deste modo, o fator ambiental acaba ficando em segundo plano, vide a grandeza dos outros problemas que são tratados com maior prioridade. Nesse ponto, como já salientado, as práticas da gestão ambiental têm benefícios não só ambientais como também econômicos e por isso, devem ser aplicadas em qualquer tipo de empresa.

Em relação à quantificação dos resíduos de madeira, estimou-se que cerca 257 toneladas desses resíduos são gerados por ano, o que representa grande perda para a empresa. Dentro dessa perspectiva, a aplicação das ferramentas como o SGA e a P+L referidas neste trabalho, podem contribuir para uma menor perda de insumos na forma de resíduos e também para a melhoria da qualidade do meio ambiente e da sociedade já que caminha no sentido de minimizar impactos ambientais.

Pôde-se perceber com o estudo de caso, que as ações sobre a gestão de resíduos de madeira ainda são corretivas, ou seja, há mais uma preocupação no final do processo, no que diz respeito ao reaproveitamento do material excedente e na destinação dos resíduos madeireiros. É fundamental uma quebra de paradigma nesse sentido, em que atitudes sejam mais preventivas e não só reativas. Além das ferramentas de gestão já citadas, esforços devem ser feitos no design ou redesign dos produtos, a fim de se buscar a redução do resíduo na fonte, bem como facilitar o gerenciamento do resíduo na produção.

\section{Agradecimentos}

Agradecimentos à FAPEMIG - Fundação de Amparo à Pesquisa do Estado de Minas Gerais e ao CNPq - Conselho Nacional de Desenvolvimento Científico e Tecnológico pelos recursos concedidos, que permitiram a realização desta pesquisa.

\section{Referências Bibliográficas}

ABDI - AGÊNCIA BRASILEIRA DE DESENVOLVIMENTO INDUSTRIAL; Núcleo de Economia Industrial E da Tecnologia do Instituto de Economia da Universidade Estadual de Campinas - UNICAMP. Relatório de Acompanhamento Setorial da Indústria Moveleira. 2008. v. 1.28 p.

ABRELPE - Associação Brasileira das Empresas de Limpeza Pública e Resíduos Especiais 2013. Panorama dos resíduos sólidos no Brasil. São Paulo, 2013. Disponível em: <http://a3p.jbrj.gov.br/pdf/ABRELPE\%20Panorama\%202001\%20 RSU-1.pdf>. Acesso em 02 jun. 2017.

AMBIENTE BRASIL. Resíduos. Disponível em: 
<http://ambientes.ambientebrasil.com.br/residuos.html>. Acesso em 02 jul. 2017.

ASSOCIAÇÃO BRASILEIRA DE NORMAS TÉCNICAS. Introdução à ABNT NBR ISO 14001:2015. São Paulo, 2015.

ASSOCIAÇÃO BRASILEIRA DE NORMAS TÉCNICAS. NBR 15164: Móveis estofados - sofás. Rio de Janeiro, 2004.

BARBIERO. L.C.S. Sistema de Gestão Ambiental - Ciclo PDCA. 2014. Disponível em: <http://graltec.com/sistema-de-gestao-ambiental-ciclo-pdca/ >. Acesso em 25 jun.2017.

CAETANO, M. D. D. E; DEPIZZOL, D. B; REIS, A. O. P. Análise do gerenciamento de resíduos sólidos e proposição de melhorias: estudo de caso em uma marcenaria de Cariacica, ES.Gest. Prod.,São Carlos, v. 24, n. 2, p. 382-394, jun. 2017.

Boyle, C. A., \& Baetz, B. W. A prototype knowledgebased decision support system for industrial waste management: part I. The decision support system. Waste Management 1998, 18(2), 87-97.

CASAGRANDE Jr. E.F; Silva M.C; CASSILHA A.C; PODLASEK C.L; MENGATTO S.N.F. Indústria moveleira e resíduos sólidos: considerações para o equilíbrio ambiental. Revista Educação \& Tecnologia 2004; 8: 209-228.

CEBDS - Conselho Empresarial Brasileiro para o Desenvolvimento Sustentável. Guia da Produção Mais Limpa: Faça você Mesmo, 2011. Disponível em: <www.pmaisl.com.br>. Acesso em 20 de jun.2017.

CNTL - Centro Nacional de Tecnologias Limpas. Curso de Formação de Consultores em Produção mais Limpa para Pequena e Microempresa. Módulo 1, Porto Alegre: CNTL, 2003.

DAIAN, G; OZARSKA.B. Wood waste management practices and strategies to increase sustainability standards in the Australian wooden furniture manufacturing, 2009. Disponível em:<https://www.researchgate.net/publication/222805974_Wood_waste_management_practice s_and_strategies_to_increase_sustainability_standards_in_the_Australian_wooden_furniture_ma nufacturing_sector>. Acesso em 26 de jun. 2017.

DEPEC - Departamento de Pesquisas e Estudos Econômicos. Indústria de Móveis. BRADESCO, 2017.

ESTOFAMINAS. Disponível em: <http://www.estofaminas.com.br/>. Acesso em 15 jun. 2017.

FIALHO, P. B. Avaliação ergonômica de processos e produtos na fabricação de estofados. Tese (Doutorado). Universidade Federal de Viçosa, Viçosa, 2011.

FIEMG. Programa de Competitividade industrial regional, 2014. Disponível em: <http://www.gdimata.com.br/wp-content/uploads/2016/10/Estudo-setorial-M\%C3\%B3veis.pdf>. Acesso em 04 jul.2017.

GIL, A. C. Métodos e técnicas de pesquisa social. 5.ed. São Paulo: Atlas, 1999.

IEMI - Inteligência Empresarial e Marketing Industrial. Relatório Brasil Móveis, 2016. Disponível em: <http://www.emobile.com.br/site/industria/iemi-relatorio-brasil-moveis-2016/>. Acesso em 10 jul.2017.

KOCH. M.R.et al. Gestão de Resíduos Sólidos de uma Empresa de Aglomerados - Um olhar para sustentabilidade. Revista Brasileira de Ciências Ambientais, n 31, Março de 2014. 
LYKIDIS, C.; GRIGORIOU, A. Hydrothermal recycling of waste and performance of the recycled wooden particleboards. Waste Management. Vol.28, p. 57-63, 2008.

LOPES, M.de A. Gerenciamento de resíduos madeireiros em pequenas indústrias de produtos de madeira de maior valor agregado, 2016. Dissertação (Mestrado em Ciências) - Escola Superior de Agricultura "Luiz de Queiroz", Universidade de São Paulo, Piracicaba, 2016.

OLIVEIRA, E. B. Desenvolvimento Sustentável e produção Limpa: Estudo de um caso em uma empresa do setor moveleiro. Porto Alegre, 2009.

PEREIRA, A. F.; CARVALHO, L. S. C.; PINTO, A. C. O. Resíduo de madeira: limites e possibilidades de seu uso como matéria-prima alternativa. In: 9o Congresso Brasileiro de Pesquisa e Desenvolvimento em Design. P\&D Design 2010. Anais... São Paulo, 2010.

PEREIRA, G. R.; SANT'ANNA, F.S.P. Uma análise da produção mais limpa no Brasil. Revista Brasileira de Ciências Ambientais - Número 24 - Junho de 2012. ISSN Impresso 1808-4524 / ISSN Eletrônico: 2176-9478.

ROSA, S. E. S. da; CORREA, A. R.; LEMOS, M. L. F.; BARROSO, D. V. O Setor de Móveis na Atualidade: uma Análise Preliminar. BNDES Setorial, Rio de Janeiro, n. 25, p. 65 - 106, mar. 2007.

SAMPIERI, R. H. et al. Metodologia de Pesquisa. 3. ed. São Paulo: MacGrawHill, 2006.

SEBRAE. Gestão sustentável nas empresas. Sustentabilidade nos pequenos negócios. 2ำed. 40p. Cuiabá, 2015a.

SEBRAE. Móveis de Madeira: Relatório de Inteligência. Santa Catarina, 2015b. Disponível em: <http://www.bibliotecas.sebrae.com.br/chronus/ARQUIVOS_CHRONUS/bds/bds.nsf/2d53684616 5a0fcf79e6478377d65618/\$File/5391.pdf> acesso em 4 jun. 2017.

SILVA, E. L; MENEZES, E. M; Metodologia da Pesquisa e Elaboração de Dissertação. Universidade Federal de Santa Catarina - Programa de Pós-Graduação em Engenharia de Produção. 3. Ed.Florianópolis, 2001

SOUZA, J. A. Aplicação de ferramentas de gestão ambiental em empresas do arranjo produtivo local de confecções do agreste pernambucano (APLCAPE). Dissertação (Mestrado em Engenharia de Produção). Centro acadêmico do Agreste- Universidade Federal de Pernambuco. Caruaru, 2015.

TUOTO, M. Levantamento sobre geração de resíduos provenientes da atividade madeireira e proposição de diretrizes para políticas, normas e condutas técnicas para promover o seu uso adequado. Ministério do meio ambiente. Secretária de Mudanças Climáticas e Qualidade Ambiental. Secretaria de Biodiversidade e Florestas Projeto PNUD BRA 00/20. Curitiba-PR, 2009.

UNEP - United Nations Environment Programme. Cleaner Production for Better Products, 2014. Disponível em: <http://www.unep.org/resourceefficiency/Business/CleanerSaferProduction/EcoInnovation/CleanerProductionforBetterProducts/tabid/78846/Default.aspx> . Acesso em 20 jun.2017.

YIN, R. K. Estudo de caso: planejamento e métodos. 2.ed. Porto Alegre: Bookman, 2001. 